\title{
QUANTIFICAÇÃO DE BIOMASSA E ESTOCAGEM DE CARBONO EM UMA FLORESTA ESTACIONAL SEMIDECIDUAL, NO PARQUE TECNOLÓGICO DE VIÇOSA, MG $^{1}$
}

\author{
Carlos Moreira Miquelino Eleto Torres², Laércio Antônio Gonçalves Jacovine³, Carlos Pedro Boechat \\ Soares $^{3}$, Silvio Nolasco Oliveira Neto ${ }^{3}$, Raul Duarte Santos ${ }^{4}$ e Fernando Castro Neto ${ }^{5}$
}

\begin{abstract}
RESUMO - Os objetivos deste trabalho foram quantificar a biomassa e a estocagem de carbono em uma Floresta Estacional Semidecidual,com área de 44,11 ha, localizado no Parque Tecnológico de Viçosa, MG e avaliar as diferenças entre as metodologias de quantificação de biomassa propostas pelo Painel Intergovernamental sobre Mudanças do Clima (IPCC) e utilizando equações regionais. Para a quantificação da biomassa e estocagem de carbono da área utilizou-se duas metodologias distintas, uma com equações regionais e outra sugerida pelo IPCC. Os estoques totais de biomassa e de carbono foram de 116,98 $\mathrm{t} \mathrm{ha}^{-1}$ e 56,31 $\mathrm{t} \mathrm{ha}^{-1}$,respectivamente, pela metodologia de equações regionais, considerando os valores acima e abaixo do solo, sub-bosque e serapilheira. E pela metodologia sugerida pelo IPCC, os estoques totais de biomassa e de carbono foram de 107,59 $\mathrm{t} \mathrm{ha}^{-1}$ e 48,70 tha-1, respectivamente. De acordo com os resultados a metodologia do IPCC subestimou a biomassa e o carbono em relação às equações regionais.
\end{abstract}

Palavras-chave: Mata Atlântica; Sequestro de carbono; Metodologias de quantificação de carbono.

\section{QUANTIFYING BIOMASS AND CARBON STOCK IN A SEASONAL SEMIDECIDUOUS FOREST IN VIÇOSA, MG, BRAZIL}

\begin{abstract}
The objectives of this study were to quantify the biomass and carbon storage in a seasonal semideciduous Forest in Viçosa, MG, with an area of 44.11 ha, and to evaluate the differences between the methods of biomass quantification proposed by the Intergovernmental Panel on Climate Change (IPCC) and by using regional equations. For biomass quantification and carbon storage in the area, were used two different methodologies, one using regional equations and another one suggested by the IPCC. The total biomass and carbon stock were $116.98 \mathrm{t} \mathrm{ha}^{-1}$ and $56.31 \mathrm{t} \mathrm{ha}^{-1}$, respectively, using the methodology of regional equations, considering the values above and below the ground, understory and litter. For the methodology suggested by the IPCC, the total biomass and carbon stock were $107.59 \mathrm{t} \mathrm{ha}^{-1}$ and $48.70 \mathrm{t} \mathrm{ha}^{-1}$, respectively. According to the results, the IPCC methodology underestimated the biomass and carbon stock, in relation to regional equations.
\end{abstract}

Keywords: Atlantic Forest; Carbon sequestration; Carbon methods quantification.

\footnotetext{
${ }^{1}$ Recebido em 15.03.2012 aceito para publicação em 06.08.2013.

${ }^{2}$ Programa de Pós-Graduação em Ciência Florestal na Universidade Federal de Viçosa, UFV, Brasil.E mail: <carlos.eleto@yahoo.com.br>.

${ }^{3}$ Departamento de Engenharia Florestal da Universidade Federal de Viçosa, UFV, Brasil. E-mail: <jacovine@ufv.br>, <csoares@ufv.br>e < snolasco@ufv.br>.

${ }^{4}$ Suzano Papel e Celulose. E-mail: <raulduartesantos@yahoo.com.br>.

${ }^{5}$ Programa de Pós-Graduação em Engenharia Florestal na Universidade Federal de Lavras, UFLA. E-mail: $<$ fernandodecastro@hotmail.com>.
} 


\section{INTRODUÇÃO}

Nas últimas Conferências das Partes (COPs) da Convenção Quadro das Nações Unidas sobre Mudança do Clima (CQNUMC) vem sendo discutida a Redução de Emissões do Desmatamento e Degradação (REDD). REDD é uma forma de pagamento por serviços ambientais em que o valor de armazenamento de carbono pelas florestas ameaçadas por desmatamento e degradação é reconhecido financeiramente (GHAZOUL et al., 2010).

Esse mecanismo está voltado particularmente para florestas nativas, e existe a probabilidade de indícios de que seja incluído na próxima negociação do Protocolo que substituirá o de Quioto. No entanto, ele já vem sendo utilizado em mercados voluntários (Não Quioto) por empresas e instituições interessadas, e padrões de verificação de créditos gerados por esse mecanismo estão aprovados e com aceitação (ABRAF, 2010).

A COP 15, realizada em Copenhagen, foi marco importante desse mecanismo, pois foram incluídos a conservação, o manejo florestal e o incremento dos estoques de carbono florestal, passando a ser chamado de REDD+ (CENAMO et al., 2010).

Para os créditos do REDD+ terem credibilidade, foram identificadas quatro principais tarefas técnicas: estimativa da biomassa e de carbono das florestas; gestão de grandes quantidades de dados espaciais; monitoramento do desmatamento e da degradação florestal; e modelagem do desmatamento futuro (HAJEK et al., 2011).

Para obter a estimativa de biomassa em determinada floresta, são necessários um inventário da vegetação por meio de parcelas, a aplicação de equações alométricas apropriadas e a extrapolação dos resultados (CHAVE et al., 2004; HENRY et al., 2010).

Segundo Vieira et al. (2008) e Ribeiro et al. (2009), apesar da grande importância biológica da Mata Atlântica, poucos estudos foram feitos com base em medições diretas de biomassa para o desenvolvimento de modelos alométricos, podendo citar os estudos realizados por Tiepolo et al. (2002) e Burger (2005). Isso se deve, segundo esses autores, pelo fato de a Mata Atlântica ser protegida por lei, tornando restrita a estimativa de biomassa por métodos diretos (destrutivos).

Ribeiro et al. (2009) afirmaram que também não há grande volume de estudos disponíveis na literatura sobre o uso de métodos indiretos para estimativa de biomassa na Mata Atlântica. Entre os estudos de quantificação de biomassa e estocagem de carbono em Florestas Estacionais Semideciduais presentes na Mata Atlântica, destacam-se aqueles de Ribeiro (2007), Boina (2008) e Amaro (2010). Assim, torna-se importante realizar pesquisas que contemplam esse assunto, a fim de preencher essa lacuna.

Diante disso, objetivou-se, com este trabalho, quantificar a biomassa e o estoque de carbono em uma Floresta Estacional Semidecidual Montana, localizado no Parque Tecnológico de Viçosa, MG, bem como avaliar as diferenças entre as metodologias de quantificação de biomassa propostas pelo IPCC e o uso de equações regionais.

\section{MATERIAL E MÉTODOS}

\subsection{Caracterização da área de estudo}

A área estudada é um fragmento florestal de 44,11 ha, localizado no Parque Tecnológico de Viçosa, com coordenadas geográficas $42^{\circ} 51 \mathrm{~W}$ e $20^{\circ} 42^{\prime} \mathrm{S}$, Viçosa, MG. Segundo a classificação de Köppen, o clima local é do tipo Cwa, tropical de altitude, com verões quentes e chuvosos e invernos frios e secos. A temperatura mínima média e máxima média anual da região é de $14^{\circ} \mathrm{C}$ e $26,1^{\circ} \mathrm{C}$, respectivamente. A umidade relativa média anual é de $80 \%$ e a precipitação média anual, de aproximadamente 1.341,2 mm (OLIVEIRA JÚNIOR, 2005).

A topografia local é acidentada com vales estreitos e úmidos. O relevo da região é predominantemente forte, ondulado e montanhoso. Os solos predominantes nos topos e nas encostas das elevações são o Latossolo Vermelho-Amarelo Álico e, nos terraços, o Podzólico Vermelho-Amarelo Câmbico (MEIRA NETO, 1997).

Segundo IBGE (1992), a vegetação do Município de Viçosa está inserida na região classificada como Floresta Estacional Semidecidual Montana. O fragmento florestal passou por vários distúrbios ao longo dos anos. Segundo informações locais, além da retirada de madeira ao longo dos anos, em parte da área que atualmente é floresta já houve pastagem, bem como plantios agrícolas e de eucalipto. Há cerca de 20 anos o plantio de eucalipto foi abandonado, e ocorreu a regeneração da vegetação nativa na área. 


\subsection{Metodologia para determinação da biomassa, utilizando equações regionais}

A vegetação foi dividida em dois níveis de abordagem. No nível I, foram utilizadas parcelas de $500 \mathrm{~m}^{2}$, e os indivíduos com DAP $\geq 5 \mathrm{~cm}$ foram identificados e mensurados. Nesse nível de abordagem, utilizou-se o método não destrutivo, ou indireto (equações regionais), para quantificar a biomassa. No nível II de abordagem, foram estabelecidas subparcelas de $5 \mathrm{~m}^{2}$ dispostas no centro de cada uma das parcelas do nível I, tendo sido obtidos a biomassa e o carbono de toda a vegetação com DAP $<5 \mathrm{~cm}$, por meio do método direto ou destrutivo.

\subsubsection{Nível I de abordagem}

Foram lançadas 22 parcelas de $500 \mathrm{~m}^{2}$ (50 x $\left.10 \mathrm{~m}\right)$ (Figura 1), onde todos os indivíduos com DAP $\geq 5$ $\mathrm{cm}$ foram identificados e tiveram sua altura total (Ht) e seu DAP mensurados.

Para obter as estimativas de biomassa e carbono do fuste das árvores, incluindo a casca, do fragmento florestal foram utilizadas as equações ajustadas por Amaro (2010), para uma Floresta Estacional Semidecidual Montana, no Município de Viçosa, MG, apresentadas a seguir:

$$
\begin{aligned}
\mathrm{BFCC} & =0,024530 * \mathrm{DAP}^{2,443356 *} \mathrm{Ht}^{0,423602} \\
\mathrm{R}^{2} & =95,01 \quad \mathrm{~S}_{\mathrm{y} \cdot \mathrm{x}}= \pm 24,2 \\
\mathrm{CFCC} & =0,010045 \cdot \mathrm{DAP}^{2,484657} \cdot \mathrm{Ht}^{0,426965} \\
\mathrm{R}^{2} & =94,74 \quad \mathrm{~S}_{\mathrm{y} \cdot \mathrm{x}}= \pm 25,1 \%
\end{aligned}
$$

A biomassa dos galhos das árvores foi estimada com base no estudo desse mesmo autor, em que se

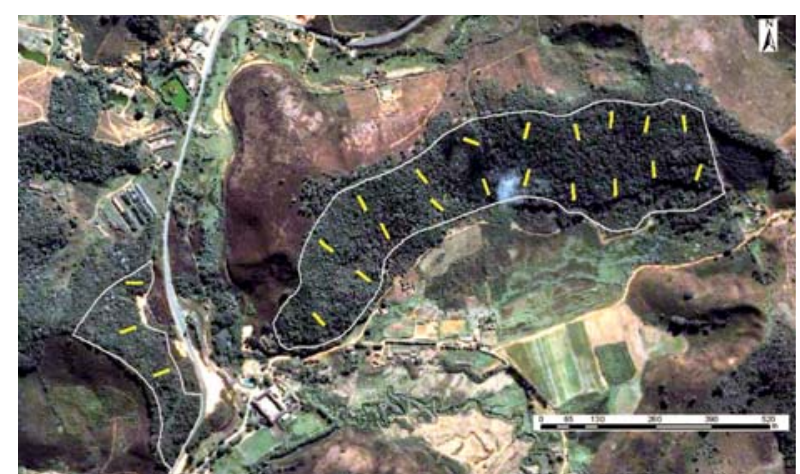

Figura 1 - Fragmento Florestal no Parque Tecnológico de Viçosa. Fonte: Google Earth

Figure 1 - Forest Fragment in the Technology Park in Viçosa.. constatou que a biomassa dos galhos com casca (BGcc) representa $25,96 \%$ da biomassa do fuste com casca:

$$
\mathrm{BGCC}=0,2596 * \mathrm{BFCC}
$$

A biomassa estocada nas folhas foi estimada com base em estudos realizados por Drumond (1996), que, avaliando duas áreas de Mata Atlântica na Região do Médio Rio Doce, constatou que a biomassa das folhas (BFO) representa $4,45 \%$ da biomassa do fuste com casca (BFCC):

$$
\mathrm{BFO}=0,0445^{*} \mathrm{BFCC}
$$

A biomassa acima do solo foi obtida por meio do somatório da biomassa dos fustes, dos galhos e das folhas.

$$
\mathrm{AGB}=\mathrm{BFCC}+\mathrm{BGCC}+\mathrm{BFO}
$$

Para estimar a biomassa das raízes (BR), considerouse que ela corresponde a $24 \%$ da biomassa do fuste com casca, conforme recomendado por Golley et al. (1978) e utilizado por Boina (2008) e Amaro (2010), em Florestas Estacionais Semideciduais:

$$
\mathrm{BR}=0,24 * \mathrm{BFCC}
$$

O carbono estocado nos galhos, nas raízes e nas folhas foi obtido multiplicando sua biomassa por 0,4854 e o teor de carbono médio, encontrado por Amaro (2010) em estudo de uma Floresta Estacional Semidecidual no Município de Viçosa, MG.

\subsubsection{Nível II de abordagem}

Dentro das subparcelas de $5 \mathrm{~m}^{2}$, toda a vegetação com DAP $<5 \mathrm{~cm}$ foi coletada e, posteriormente, pesada. Desse material, foram retiradas amostras que, depois de coletadas e pesadas, ainda úmidas, foram levadas para o laboratório. Essas amostras foram colocadas em estufa de circulação forçada de ar, a uma temperatura de aproximadamente $65^{\circ} \mathrm{C}$ até a estabilização do peso de matéria seca.

A determinação da biomassa seca foi obtida por meio do método da proporcionalidade (SOARES; OLIVEIRA, 2002). Para isso, utilizou-se a seguinte fórmula:

$$
\operatorname{MS}(c)=\operatorname{Mu}(a) * \operatorname{Ms}(a) / M u(a)
$$

em que:

MS (c) = massa de matéria seca total no campo, em kg;

Ms (a) = massa de matéria seca das amostras, em kg;

Revista Árvore, Viçosa-MG, v.37, n.4, p.647-655, 2013 
Mu (a) = massa de matéria úmida das amostras, em $\mathrm{kg}$; e

$\mathrm{Mu}$ (c) = massa de matéria úmida total no campo, em kg.

Os cálculos foram efetuados utilizando a média dos valores encontrados da massa de matéria úmida no campo, a massa de matéria úmida e a massa de matéria seca das amostras. Posteriormente, os valores encontrados foram extrapolados para toneladas por hectare.

\subsubsection{Quantificação da biomassa da serapilheira}

A biomassa da serapilheira foi quantificada por meio da coleta do material na superfície do solo, em dois pontos definidos próximos ao centro das parcelas do nível I de abordagem, a 12,5 m de comprimento e $5 \mathrm{~m}$ de largura da borda das parcelas. Na coleta, utilizouse um gabarito de área interna de $1 \mathrm{~m}^{2}$. Dessa forma, foram retiradas e pesadas as amostras do material que, posteriormente, foram secas em estufa de circulação forçada de ar a uma temperatura de aproximadamente $65^{\circ} \mathrm{C}$ até a estabilização do seu peso de matéria seca. A determinação da biomassa seca total também foi obtida pelo método da proporcionalidade, conforme descrito anteriormente para determinação da biomassa da vegetação de porte baixo. Os cálculos foram efetuados utilizando-se a média dos valores encontrados do peso de matéria úmida e seca das amostras. Os valores encontrados foram extrapolados para toneladas por hectare.

\subsection{Metodologia estabelecida pelo IPCC para determinação da biomassa}

Para avaliar essa metodologia, foram utilizados os dados das 22 parcelas de $500 \mathrm{~m}^{2}$ (50 x $10 \mathrm{~m}$ ) para amostragem da vegetação no nível I de abordagem.

A biomassa acima do solo (AGB) foi estimada por meio do método não destrutivo de quantificação, utilizando-se a equação alométrica (equação 8), proposta por Brown et al. (1989), aceita pelo IPCC (2003) e pelo Centro de Gestão e Estudos Estratégicos (2008). Essa equação se aplica a florestas de regiões tropicais úmidas, com pluviosidade menor que $1.500 \mathrm{~mm}$ anuais, e a indivíduos com DAP variando entre 5 e $40 \mathrm{~cm}$. Para esta pesquisa, essa equação foi usada para todos os indivíduos com DAP $\geq 5$, a fim de verificar a diferença entre as metodologias utilizadas.

$\mathrm{AGB}=34,4703-8,0671 * \mathrm{DAP}+0,6589 * \mathrm{DAP}^{2}$ em que:

AGB = biomassa acima do solo, em kg; e

DAP = diâmetro à altura do peito, em cm.

Para a Attalea dubia (Indaiá), por se tratar de uma palmeira, existe a necessidade de se utilizar uma equação alométrica específica (equação 9), proposta pelo IPCC (2003).

$$
\mathrm{AGB}=10,856+176,76^{*} \mathrm{Ht}-6,898^{*} \mathrm{Ht}
$$

em que:

$\mathrm{Ht}=$ altura total, em $\mathrm{m}$.

A biomassa abaixo do solo (BGB) foi estimada com base na equação alométrica proposta por Cairns et al. (1997) e sugerida pelo IPCC (2003) para florestas tropicais (equação 10).

$$
\mathrm{BGB}=\exp [-1,0587+0,8836 * \ln (\mathrm{AGB})]
$$

\subsubsection{Quantificação da biomassa do sub-bosque e da serapilheira}

Para quantificação da biomassa da vegetação com o DAP $<5$ cm e da serapilheira, segundo a recomendação do IPCC (2003), foram estabelecidas quatro subparcelas de $0,5 \mathrm{~m}^{2}$, dispostas em cada uma das 22 parcelas. Todo material encontrado dentro das subparcelas foi cortado, homogeneizado por parcela e pesado. Retiraram-se amostras para determinação da massa seca, obtida pelo método da proporcionalidade.

\subsubsection{Carbono estocado na biomassa}

O carbono estocado na biomassa foi estimado por meio da multiplicação dos valores de biomassa pelo fator 0,47 para espécies arbóreas e herbáceas e 0,37 para serapilheira, conforme recomendação do IPCC (2006).

Para a vegetação do nível II de abordagem e da serapilheira, na metodologia com equações regionais, em que foi utilizado o método destrutivo para quantificação da biomassa, obteve-se o teor de carbono. Primeiramente, as amostras foram moídas em moinho tipo Willey, marca Thomas Scientific, retirando-se subamostras de $1 \mathrm{~g}$ para serem analisadas no Laboratório de Solos Florestais da Universidade Federal de Viçosa, em Viçosa, MG.

Cada amostra de $1 \mathrm{~g}$ foi colocada em um cadinho de porcelana sem tampa, levado à mufla, modelo Linn Elektro Therm, na temperatura de $550^{\circ} \mathrm{C}$, por $3 \mathrm{~h}$, até 
a completa calcinação da amostra. A amostra foi retirada da mufla e resfriada em dissecador para posterior pesagem em balança com precisão de 0,0001 g, modelo MARK 210A. O teor de carbono foi calculado pela equação 11.

$$
C T=\left(\frac{M_{S}}{M_{r}}\right) * 100
$$

em que:

$\mathrm{CT}=$ teor de carbono, em \%;

Ms = massa do resíduo da amostra seca após a calcinação, em g; e

$\mathrm{Mr}=$ massa da amostra seca, em g.

\subsection{Diferença entre as metodologias}

Para análise das diferenças de estocagem de biomassa e carbono entre as metodologias, utilizouse a equação 12 .

$$
D f=\left(\frac{M_{I P C C}-M_{\operatorname{Re} g}}{M_{I P C C}}\right) * 100
$$

em que:

Df = diferença entre as metodologias, em \%;

$\mathrm{M}_{\mathrm{IPCC}}=$ estoque de biomassa e carbono pela metodologia do IPCC, em tha-1; e

$\mathrm{M}_{\text {Reg }}=$ estoque de biomassa e carbono pela metodologia utilizando equações regionais, em $\mathrm{t} \mathrm{ha}^{-1}$.

Para comparação entre as médias de biomassa e carbono total das metodologias do IPCC e utilizando equações regionais, aplicou-se o teste t para amostras dependentes, a 95\% de probabilidade. Já para comparação entre a biomassa acima e abaixo do solo das metodologias, nas diferentes classes diamétricas, utilizou-se o teste qui-quadrado a $95 \%$ de probabilidade.

\section{RESULTADOS}

\subsection{Estoque de biomassa}

A estimativa de biomassa média para o fragmento florestal, com o uso de equações regionais de Amaro (2010), Drumond (1996) e Golley et al. (1978), foi de 98,46 t ha-1. A biomassa acima do solo das espécies arbóreas foi estimada em 80,41 tha-1 (81,68\%); a biomassa acima do solo dos indivíduos de Attalea dubia, em 2,74 t.ha-1 (2,78\%); a biomassa abaixo do solo das espécies arbóreas, em 14,80 t ha-1 (15,03\%); e a biomassa abaixo do solo dos indivíduos de Attalea dubia, em 0,50 t ha$^{-1}(0,51 \%)$ (Tabela 1$)$.

Com o uso de equações propostas pelo IPCC, a estimativa de biomassa média para o fragmento florestal foi de 89,41 t ha-1 . A biomassa acima do solo das espécies arbóreas foi estimada em 72,80 tha-1 $(81,42 \%)$; a biomassa acima do solo de Attalea dubia, em 1,82 t ha-1 (2,04\%); a biomassa abaixo do solo das espécies arbóreas, em 14,51 t ha-1 $^{-1}(16,22 \%)$; e a biomassa abaixo do solo de Attalea dubia, em 0,28 tha-1 (0,32\%) (Tabela 1).

As estimativas de biomassa total pela metodologia sugerida pelo IPCC e utilizando equações regionais foram estatisticamente diferentes pelo teste t a $95 \%$ de probabilidade $(\mathrm{P}=0,001512)$.

A metodologia sugerida pelo IPCC obteve tendência de subestimação dos valores de estocagem de biomassa em relação à metodologia com equações regionais. Em média, a estimativa de biomassa pela metodologia do IPCC foi 9,11\% menor que a utilizada nas equações regionais. Uma possível explicação para essa subestimação é a não inclusão da variável altura no modelo, que introduz um viés (“bias”) nas estimativas.

Para estimativa da biomassa acima do solo, usando a metodologia proposta pelo IPCC (Tabela 2), houve superestimação nas classes diamétricas de 7,5 e 52,5 cm e subestimação nas demais classes. A maior diferença média de estocagem de biomassa entre as metodologias se verificou na classe de $12,5 \mathrm{~cm}(-18,04 \%)$ e a menor diferença média, na classe de 52,5 cm (0,76\%), o que pode ser explicado pelo fato de apenas uma parcela apresentar árvores nessa classe, deixando a média próxima a zero. No entanto, pelo teste qui-quadrado não houve diferenças estatísticas, a 95\% de probabilidade, entre as estimativas por classes diamétricas.

Para a biomassa abaixo do solo ocorreu, em média, a superestimação nas classes de 7,5 cm e 12,5 cm, e nas outras classes diamétricas houve subestimação das estimativas pela metodologia do IPCC, em comparação com o uso de equações regionais. A maior diferença foi encontrada na classe de 7,5 cm (39,13\%), enquanto a menor (-0,08\%) foi observada na classe de $52,5 \mathrm{~cm}$. Na biomassa abaixo do solo, o teste qui-quadrado não foi significativo a $95 \%$ de probabilidade.

\subsection{Estoque de carbono no componente arbóreo}

A estimativa média de carbono para o fragmento florestal, com o uso de equações regionais, foi de

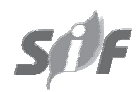

Revista Árvore, Viçosa-MG, v.37, n.4, p.647-655, 2013 
Tabela 1 - Estoque de biomassa utilizando equações regionais e metodologia do IPCC. Table 1 - Biomass storage using regional equations and the IPCC methodology.

\begin{tabular}{|c|c|c|c|c|c|c|}
\hline \multirow[b]{2}{*}{ Biomassa } & \multicolumn{3}{|c|}{ Equações Regionais } & \multicolumn{3}{|c|}{ IPCC } \\
\hline & $\begin{array}{l}\text { Média } \\
\left(\mathrm{t} \mathrm{ha}^{-1}\right)\end{array}$ & $\begin{array}{l}\text { Desvio } \\
\text { Padrão }\end{array}$ & $\begin{array}{c}\text { Biomassa } \\
(\%)\end{array}$ & $\begin{array}{l}\text { Média } \\
(\mathrm{t} \mathrm{ha-1)}\end{array}$ & $\begin{array}{l}\text { Desvio } \\
\text { Padrão }\end{array}$ & $\begin{array}{c}\text { Biomassa } \\
(\%)\end{array}$ \\
\hline Acima do Solo (espécies arbóreas) & 80,41 & $\pm 31,69$ & 81.68 & 72,80 & $\pm 27,48$ & 81,42 \\
\hline Acima do Solo Attalea dubia & 2,74 & $\pm 10,28$ & 2,78 & 1,82 & $\pm 5,93$ & 2,04 \\
\hline Abaixo do Solo (espécies arbóreas) & 14,80 & $\pm 5,83$ & 15,03 & 14,51 & $\pm 4,58$ & 16,22 \\
\hline Abaixo do Solo Attalea dubia & 0,50 & $\pm 1,89$ & 0,51 & 0,28 & $\pm 0,92$ & 0,32 \\
\hline Total & 98,45 & $\pm 38,35$ & 100,00 & 89,41 & $\pm 32,75$ & 100,00 \\
\hline
\end{tabular}

Tabela 2 - Diferença em porcentagem (\%) do estoque de biomassa acima e abaixo do solo ( $\mathrm{t} \mathrm{ha}^{-1}$ ) usando a metodologia do IPCC e pelo uso de equações regionais, por classe de DAP.

Table 2 - Difference in percentage of biomass storage above and below the ground using the IPCC methodology and regional equations, by DBH class.

\begin{tabular}{|c|c|c|c|c|c|c|c|c|c|c|c|c|}
\hline \multirow{2}{*}{ Biomassa } & & \multicolumn{11}{|c|}{ Classe diamétrica } \\
\hline & & 7,5 & 12,5 & 17,5 & 22,5 & 27,5 & 32,5 & 37,5 & 42,5 & 52,5 & 57,5 & 62,5 \\
\hline $\begin{array}{l}\text { Acima } \\
\text { do Solo }\end{array}$ & $\begin{array}{c}\text { Média } \\
\text { Desvio Padrão }\end{array}$ & $\begin{array}{l}13,94 \\
\pm 5,70\end{array}$ & $\begin{array}{c}-18,04 \\
\pm 6,83\end{array}$ & $\begin{array}{c}-13,76 \\
\pm 8,49\end{array}$ & $\begin{array}{c}-11,53 \\
\pm 9,36\end{array}$ & $\begin{array}{l}-7,88 \\
\pm 9,43\end{array}$ & $\begin{array}{c}-9,22 \\
\pm 12,76\end{array}$ & $\begin{array}{l}-4,75 \\
\pm 9,55\end{array}$ & $\begin{array}{c}-2,66 \\
\pm 10,21\end{array}$ & $\begin{array}{c}0,76 \\
\pm 3,48\end{array}$ & $\begin{array}{l}-1,95 \\
\pm 8,92\end{array}$ & $\begin{array}{l}-1,70 \\
\pm 7,78\end{array}$ \\
\hline $\begin{array}{l}\text { Abaixo } \\
\text { do Solo }\end{array}$ & $\begin{array}{c}\text { Média } \\
\text { Desvio Padrão }\end{array}$ & $\begin{array}{l}39,13 \\
\pm 4,18\end{array}$ & $\begin{array}{r}5,16 \\
\pm 5,83\end{array}$ & $\begin{array}{l}-2,28 \\
\pm 7,79\end{array}$ & $\begin{array}{l}-8,20 \\
\pm 8,42\end{array}$ & $\begin{array}{l}-10,29 \\
\pm 10,67\end{array}$ & $\begin{array}{l}-14,79 \\
\pm 17,14\end{array}$ & $\begin{array}{c}-8,48 \\
\pm 16,33\end{array}$ & $\begin{array}{c}-6,77 \\
\pm 16,10\end{array}$ & $\begin{array}{l}-0,08 \\
\pm 0,37\end{array}$ & $\begin{array}{c}-3,69 \\
\pm 16,89\end{array}$ & $\begin{array}{r}-3,59 \\
\pm 16,47\end{array}$ \\
\hline
\end{tabular}

46,76 tha $\mathrm{ha}^{-1}$. O carbono acima do solo das espécies arbóreas foi estimado em 38,00 t ha-1 $(81,26 \%)$; o carbono acima do solo das Attalea dubia, em 1,34 tha-1 (2,86\%); o carbono abaixo do solo das espécies arbóreas, em 7,18 t ha-1 (15,36\%); e o carbono abaixo do solo de Attalea dubia, em 0,24 t ha-1 (0,52\%). A parcela 10 obteve a maior estimativa de carbono $\left(87,02 \mathrm{t} \mathrm{ha}^{-1}\right)$, enquanto a parcela 5 , a menor estimativa (19,40 tha-1).

A estimativa média de carbono, utilizando equações propostas pelo IPCC, foi de 42,03 $\mathrm{t} \mathrm{ha}^{-1}$. A estocagem de carbono acima do solo das espécies arbóreas foi estimada em 34,22 t ha-1 $(81,42 \%)$; o carbono acima do solo de Attalea dubia, em 0,86 tha-1 (2,04\%); o carbono abaixo do solo das espécies arbóreas, em 6,82 $\mathrm{tha}^{-1}$ (16,22\%); e o carbono do solo de Attalea dubia, em 0,13 tha $^{-1}(0,32 \%)$. A parcela 10 obteve a maior estimativa de carbono, 71,75 t ha-1, enquanto a parcela 8 , a menor $\left(20,25\right.$ t ha$\left.^{-1}\right)$.

As estimativas de carbono total, pela metodologia sugerida pelo IPCC e utilizando equações regionais, foram estatisticamente diferentes pelo teste t a 5\% de probabilidade $(\mathrm{P}=0,001049)$.

Revista Árvore, Viçosa-MG, v.37, n.4, p.647-655, 2013

\subsection{Biomassa e carbono do sub-bosque e da serapilheira}

O sub-bosque apresentou biomassa média de $6,96 \mathrm{t} \mathrm{ha}^{-1}$, porém com alto desvio- padrão $\left( \pm 6,19 \mathrm{t} \mathrm{ha}^{-1}\right)$, devido à grande diferença entre as biomassas das parcelas. Em relação à serapilheira, o fragmento florestal apresentou biomassa média equivalente a 11,57 t ha-1 (Tabela 3).

Pela metodologia estabelecida pelo IPCC, o subbosque e a serapilheira apresentaram biomassa de 5,10 e 11,54 t ha $^{-1}$, respectivamente. Houve variação entre as parcelas, tanto para o sub-bosque $( \pm 4,05)$ quanto para a serapilheira $( \pm 6,15)$ (Tabela 3$)$. Segundo Figueiredo Filho et al. (2005), vários fatores abióticos e bióticos como tipo de vegetação, precipitação, altitude, temperatura, latitude, luminosidade, relevo, deciduosidade, estágio sucessional, disponibilidade hídrica e características do solo afetam a produção de serapilheira. E dependendo das características de cada ecossistema, determinado fator pode prevalecer sobre os demais.

O teor médio de carbono na biomassa foi de 52,79\% e 52,02\%, para o sub-bosque e serapilheira, respectivamente. $\mathrm{O}$ estoque de carbono para o sub- 
Tabela 3 - Estoque de biomassa (t.ha-1) e carbono (t.ha-1) para sub-bosque e serapilheira. Table 3 - Biomass and carbon storage for understory and litter.

\begin{tabular}{|c|c|c|c|c|c|}
\hline \multirow{2}{*}{ Metodologia } & & \multicolumn{2}{|c|}{ Biomassa (t ha-1) } & \multicolumn{2}{|c|}{ Carbono (t ha $\left.{ }^{-1}\right)$} \\
\hline & & Sub-bosque & Serapilheira & Sub-bosque & Serapilheira \\
\hline Regional & $\begin{array}{c}\text { Média } \\
\text { Desvio Padrão }\end{array}$ & $\begin{array}{c}6,96 \\
( \pm 6,19)\end{array}$ & $\begin{array}{c}11,57 \\
( \pm 4,14)\end{array}$ & $\begin{array}{c}3,73 \\
( \pm 3,34)\end{array}$ & $\begin{array}{c}5,82 \\
( \pm 2,10)\end{array}$ \\
\hline IPCC & $\begin{array}{c}\text { Média } \\
\text { Desvio Padrão }\end{array}$ & $\begin{array}{c}5,10 \\
( \pm 4,05)\end{array}$ & $\begin{array}{c}11,54 \\
( \pm 6,15)\end{array}$ & $\begin{array}{c}2,40 \\
( \pm 1,90)\end{array}$ & $\begin{array}{c}4,27 \\
( \pm 2,28)\end{array}$ \\
\hline
\end{tabular}

bosque foi de 3,73 $\mathrm{t} \mathrm{ha}^{-1}$ e para serapilheira, 5,82 $\mathrm{t} \mathrm{ha}^{-1}$. Pela metodologia estabelecida pelo IPCC, o subbosque e a serapilheira apresentaram biomassa de 2,40 e 4,27 t ha-1, respectivamente (Tabela 3).

\subsection{Biomassa e carbono total}

Para o Fragmento Florestal, a biomassa total foi igual a 116,98 $\mathrm{t} \mathrm{ha}^{-1}$ pela metodologia de equações regionais, composta por $71,08 \%$ de biomassa acima do solo; 13,08\% de biomassa abaixo do solo; 5,95\% no sub-bosque; e 9,89\% na serapilheira. Já a biomassa total pela metodologia do IPCC foi de 107,59 $\mathrm{t} \mathrm{ha}^{-1}$, constituída por $69,36 \%$ de biomassa acima do solo; $15,18 \%$ de biomassa abaixo do solo; $4,74 \%$ no subbosque; e 10,73\% na serapilheira (Figura 2).

\section{DISCUSSÃO}

A estimativa de biomassa para o fragmento estudado foi superior ao encontrado por Boina (2008), em uma área com Floresta Estacional Semidecidual localizada no Vale do Rio Doce, MG, que encontrou uma estimativa de biomassa acima do solo de 73,39 t.ha-1 . Porém, foi inferior ao encontrado pela mesma autora em outro fragmento florestal, no Vale do Rio Doce, MG (152,35 t.ha-1); e ao encontrado por Amaro (2010), que obteve estimativa de biomassa acima do solo e de raízes de 197,73 t.ha-1 para indivíduos com DAP e” $5 \mathrm{~cm}$, em uma Floresta Estacional Semidecidual, no Município de Viçosa, MG.

Vilar (2009), utilizando a equação proposta por Brown et al. (1989) e aceita pelo IPCC (2003), encontrou uma estimativa de 119,44 t.ha-1 para biomassa acima do solo em matas ciliares na Zona da Mata mineira.

Em relação ao carbono, as estimativas encontradas por meio das diferentes metodologias utilizadas ficaram abaixo das encontradas por Amaro (2010), que obteve uma estimativa de carbono acima do solo e de raízes de 90,01 t ha-1, para indivíduos com DAP $\geq 5 \mathrm{~cm}$, em

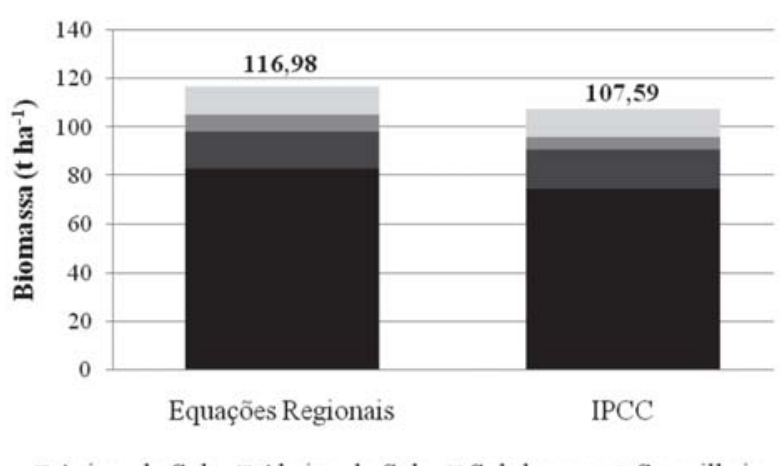

- Acima do Solo a Abaixo do Solo = Sub-bosque $=$ Serapilheira

Figura 2 - Biomassa total para o Fragmento Florestal utilizando equações regionais e pelo IPCC.

Figure 2 - Total biomass for the forest fragment using regional equations and the IPCC.

uma Floresta Estacional Semidecidual, no Município de Viçosa, MG, e de Ribeiro (2007), em uma Floresta Estacional Semidecidual primária no mesmo município, onde foi estimada uma estocagem de carbono acima do solo igual a 83,34 t.ha-1.

A estimativa de carbono presente na área de estudo foi considerada baixa se comparada com outros fragmentos na região. Porém, como o fragmento se apresenta em estágio secundário médio de sucessão, há tendência de continuidade do seu crescimento, aumentando, com isso, o estoque de biomassa e de carbono nos próximos anos. Comparar resultados de biomassa de forma ampla é tarefa difícil, principalmente da vegetação arbustiva (sub-bosque), pois não existe literatura disponível sobre o tema proposto (WATZLAWICK et al., 2005).

Os valores de biomassa para o sub-bosque foram inferiores aos encontrados por Amaro (2010) (8,10 t ha-1) para floresta com a mesma fitofisionomia, localizada em Viçosa, MG. Porém, o mesmo autor encontrou valores 
inferiores para a biomassa da serapilheira. Coutinho (2009), estudando a biomassa em uma floresta secundária no domínio da Mata Atlântica, no Município de Cruzeiro, $\mathrm{SP}$, observou uma estocagem de 7,78 $\mathrm{t} \mathrm{ha}^{-1}$ para o subbosque e de $8,22 \mathrm{t} \mathrm{ha}^{-1}$ para a serapilheira.

Os teores de carbono para o sub-bosque e serapilheira foram superiores aos valores estabelecidos pelo default do IPCC (2006), que sugere $47 \%$ para o sub-bosque e $37 \%$ para a serapilheira. Também foram superiores aos encontrados por Higuchi e Carvalho Júnior (1994), que observaram teor médio na serapilheira de 39,3\% para Floresta Tropical de Terra Firme na Região Amazônica; e Ferez (2010), que aplicou o fator 0,42 para a conversão da produção de serapilheira anual para estoque de carbono, em uma Floresta Estacional Semidecidual, em Anhembi, SP.

O estoque de carbono médio para o sub-bosque foi inferior ao encontrado por Watzlawick et al. (2002), que, estudando a fixação de carbono em Floresta Ombrófila Mista, em diferentes estágios de regeneração, encontraram estocagem de carbono no sub-bosque para estágio inicial de sucessão igual a 9,60 t ha-1 , 8,46 t ha ${ }^{-1}$ para o intermediário e 8,03 t ha ${ }^{-1}$ para o avançado. Porém, para a serapilheira, a estocagem de carbono foi superior ao encontrado por esses mesmos autores, 2,99 t ha ${ }^{-1} ; 3,30 \mathrm{t} \mathrm{ha}^{-1}$ e 2,90 t ha ${ }^{-1}$ para os estágios inicial, intermediário e avançado de sucessão, respectivamente.

O default do IPCC (2006) para o estoque de carbono em serapilheira para florestas tropicais maduras é de $2,1 \mathrm{t} \mathrm{ha}^{-1}$, valor inferior ao encontrado neste trabalho.

\section{CONCLUSÃO}

A metodologia do IPCC apresentou tendência de subestimar a biomassa e o carbono, em comparação com as metodologias regionais. Apesar disso, sua utilização é de grande importância para nortear pesquisas de carbono, principalmente quando não existem equações alométricas apropriadas para cada região. Ressalta-se também que, adotando o princípio conservador nas estimativas, conforme recomendado em projetos de carbono, a metodologia do IPCC pode ser utilizada.

A diferença da estocagem de carbono auferida utilizando as metodologias do IPCC e as equações regionais permite concluir sobre a necessidade de estudos em outras florestas, visando obter padronização nas metodologias de quantificação de biomassa e estocagem de carbono das florestas, além de melhorar os bancos de dados e as bases comparativas entre os estudos.

\section{AGRADECIMENTOS}

Ao CNPq e à FAPEMIG, pela concessão de bolsas e pelo financiamento da pesquisa; e ao Parque Tecnológico de Viçosa e ao CENTEV, pela concessão da área de estudo.

\section{REFERÊNCIAS}

ABRAF. Anuário estatístico da ABRAF 2010: ano base 2009. Brasília: 2010. 104p.

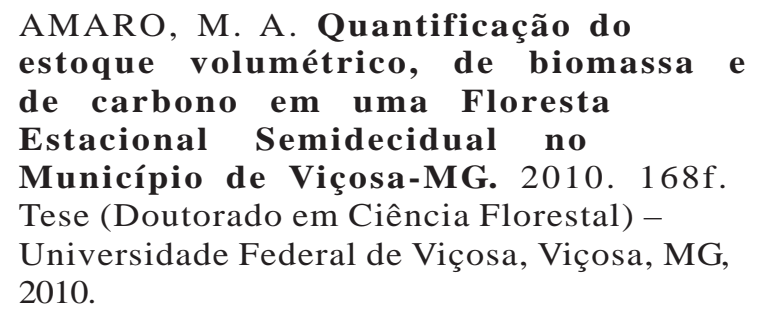

BOINA, A. Quantificação de estoques de biomassa e de carbono em Floresta Estacional Semidecidual, Vale do Rio Doce, Minas Gerais. 2008. 89f. Dissertação (Mestrado em Ciência Florestal) - Universidade Federal de Viçosa, Viçosa, MG, 2008.

BROWN, S.; GILLESPIE, A. J. R.; LUGO, A. E. Biomass estimation methods for tropical forests with applications to forest inventory data. Forest Science, v.35, p.881-902, 1989.

BURGER, R. D. M. Modelos alométricos para a estimativa da fitomassa de Mata Atlântica na Serra do Mar, SP. 2005.112f. Tese (Doutorado em Ciências) Universidade de São Paulo, São Paulo, 2005.

CAIRNS, M. A. et al. Root biomass allocation in the world's upland forests. Oecologia, v. 111, p. 1-11, 1997.

CENAMO, M. C. et al. Guia sobre Projetos REDD+ na América Latina. Manaus: 2010. 96p. 
CENTRO DE GESTÃO E ESTUDOS

ESTRATÉGICOS - CGEE. Manual de capacitação sobre mudança do clima e projetos de mecanismo de desenvolvimento limpo (MDL) Brasília, DF: 2008. 276p.

CHAVE, J. et al. Error propagation and scaling for tropical forest biomass estimates.

Philosophical Transactions of the Royal Society, v.359, n.1443, p.409-420, 2004.

COUTINHO, R. P. Estoques de carbono e emissão de $n_{2} 0$ no sistema solo-planta em Região da Mata Atlântica. 2009. $57 \mathrm{f}$. Dissertação (Mestrado em Ciências) -

Universidade Federal Rural do Rio de Janeiro, Seropédica, 2009.

DRUMOND, M. A. Alterações fitossociológicas e edáficas decorrentes de modificações da cobertura vegetal na Mata Atlântica, região do Médio Rio Doce, MG. 1996. 73f. Tese (Doutorado em Ciência Florestal) - Universidade Federal de Viçosa, Viçosa, MG, 1996.

FEREZ, A. P. C. Efeito de práticas silviculturais sobre as taxas iniciais de sequestro de carbono em plantios de restauração da Mata Atlântica. 2010. 106f. Dissertação (Mestrado em Ciências) Universidade de São Paulo, São Paulo, 2010.

FIGUEIREDO FILHO, A. et al. Produção estacional de serapilheira em uma floresta Ombrófila Mista na Floresta Nacional de Irati (PR). Ambiência - Revista do Centro de Ciências Agrárias e Ambientais, v.1, n.2, p.257-269, 2005.

GHAZOUL, J. et al. REDD: a reckoning of environment and development implications. Trends in Ecology and Evolution, v.25, n.7, p.396-402, 2010.

GOLLEY, F. B. et al. Ciclagem de minerais em um ecossistema de Floresta Tropical Úmida. São Paulo: EDUSP, 1978. 256p.

HAJEK, F. et al. Regime-building for REDD+: Evidence from a cluster of local initiatives in south-eastern Peru. Environmental Science \& Policy, v.14, n.2, p.201-215, 2011.
HENRY, M. et al. Wood density, phytomass variations within and among trees, and allometric equations in a tropical rainforest of Africa. Forest Ecology and Management, v.260, n.5, p.1375-1388, 2010.

HIGUCHI, N.; CARVALHO JUNIOR, J. A.

Fitomassa e conteúdo de carbono de espécies arbóreas da Amazônia. In: EMISSÃO × SEQUESTRO DE $\mathrm{CO}_{2}$ - UMA NOVA OPORTUNIDADE DE NEGÓCIOS PARA O BRASIL, 1994. Rio de Janeiro: Companhia Vale do Rio Doce, 1994. p.125-153.

\section{INSTITUTO BRASIEIRA DE GEOGRAFIA E} ESTATISTICA - IBGE. Manual técnico da vegetação brasileira. Manuais técnicos em geociências número 1. Rio de Janeiro: 1992. 92p.

INTERGOVERNMENTAL PANEL ON CLIMATE CHANGE - IPCC. Good practice guidance for land use, land-use change and forestry. Japan: Institute for Global Environmental Strategies (IGES), 2003.

\section{INTERGOVERNMENTAL PANEL ON CLIMATE} CHANGE - IPCC. Guidelines for National Greenhouse Gas Inventories: agriculture, forestry and other land use. Japan: Institute for Global Environmental Strategies (IGES), 2006. v.4.

MEIRA NETO, J. A. A. Estudos florísticos, estruturais e ambientais nos estratos arbóreo e herbáceos-arbustivo de uma floresta estacional semidecidual em Viçosa, MG. 1997. 154f. Tese (Doutorado em Ciências Biológicas) - Universidade Estadual de Campinas, Campinas, 1997.

\section{OLIVEIRA JUniOR, J. C. Precipitação} efetiva em floresta estacional semidecidual na reserva Mata do Paraíso, Viçosa, Minas Gerais. 2005. $72 \mathrm{f}$. Dissertação (Mestrado em Ciência Florestal) Universidade Federal de Viçosa, Viçosa, MG, 2005.

RIBEIRO, S. C. Quantificação do estoque de biomassa e análise econômica da implementação de projetos visando à geração de créditos de carbono em pastagem, capoeira e floresta primária. 2007. 128f. Dissertação (Mestrado em Ciência Florestal) - Universidade Federal de Viçosa, Viçosa, MG, 2007.

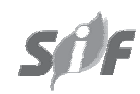

Revista Árvore, Viçosa-MG, v.37, n.4, p.647-655, 2013 
RIBEIRO, S. C. et al. Quantificação de biomassa e estimativa de estoque de carbono em uma floresta madura no município de Viçosa, Minas Gerais. Revista Árvore, v.33, n.5, p.917-926, 2009.

SOARES, C. P. B.; OLIVEIRA, M. L. R. Equações para estimar a quantidade de carbono na parte aérea de árvores de eucalipto em Viçosa, Minas Gerais. Revista Árvore, v.26, n.5, p. 533-539, 2002.

TIEPOLO, G.; CALMON, M.; FERETTI, A. R. Measuring and monitoring carbon stocks at the Guaraqueçaba climate action project, Paraná, Brazil. In: INTERNATIONAL SYMPOSIUM ON FOREST CARBON SEQUESTRATION AND MONITORING, 2002, Taipei, Taiwan. Anais... Taipei: Taiwan Forestry Research Institute, 2002. p.98-115.
VIEIRA, S. A. et al. Estimation of biomass and carbon stocks: the case of the Atlantic Forest. Biota Neotropica, v.8, n.2, p.21-29, 2008.

VILAR, M. B. Valoração econômica de serviços ambientais em propriedades rurais. 2009, $146 f$. Dissertação (Mestrado em Ciência Florestal) Universidade Federal de Viçosa, Viçosa, MG, 2009.

WATZLAWICK, L. F. et al. Fixação de carbono em Floresta Ombrófila Mista em diferentes estágios de regeneração. In: SANQUETTA, C. R. et al. (Ed.). As florestas e o carbono. Curitiba: Imprensa Universitária da UFPR, 2002. p.153-173.

WATZLAWICK, L. F.; SANQUETTA, C. R.; CALDEIRA, M. V. W. Estoque de carbono orgânico e biomassa em Pinus taeda L. Biomassa \& Energia, v.2, n.1, p.7-17, 2005. 